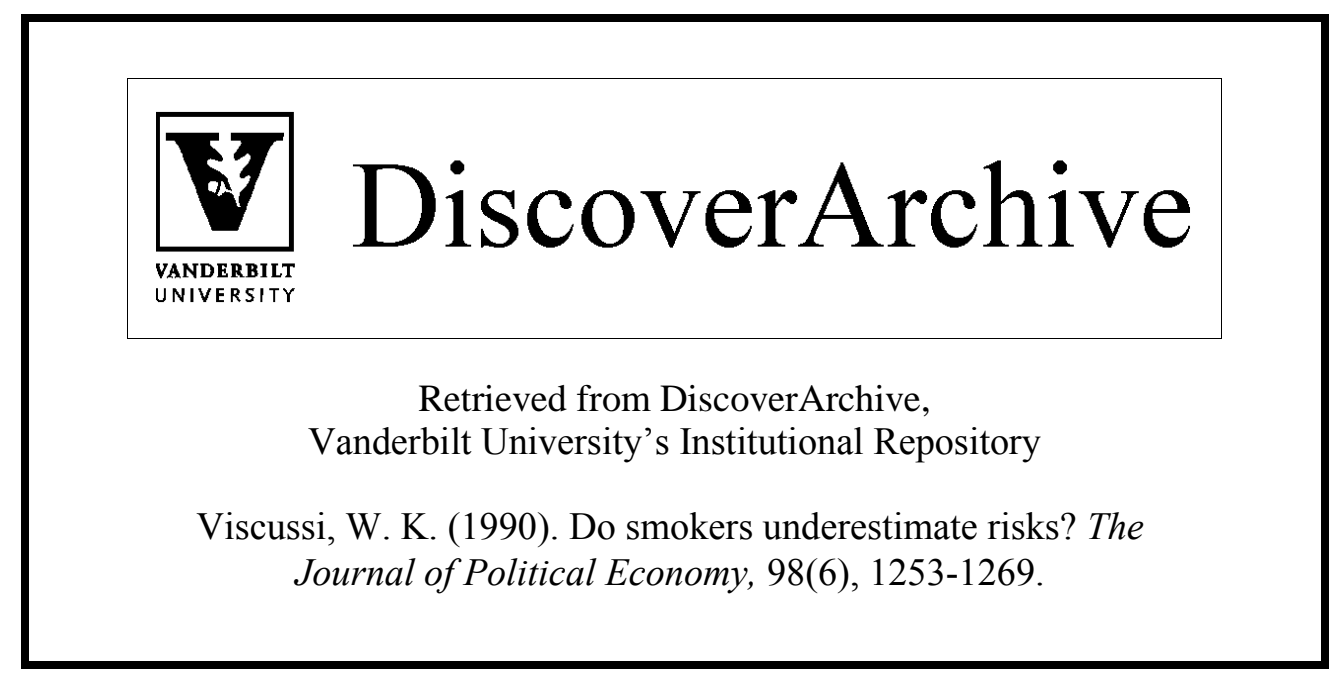




\section{Do Smokers Underestimate Risks?}

\section{W. Kip Viscusi}

Duke University

This paper uses a national survey of 3,119 individuals to examine the effect of lung cancer risk perceptions on smoking activity. Both smokers and nonsmokers greatly overestimate the lung cancer risk of cigarette smoking, and the extent of the overestimation is much greater than the extent of underestimation. These risk perceptions in turn significantly reduce the probability of smoking, as suggested by an economic model of risky consumption decisions. Cigarette excise taxes in effect endow individuals with additional risk perceptions comparable to their current assessed lung cancer risks.

\section{Introduction}

Individuals face a multitude of risks in their daily lives. For the most part, these risks arise because of particular actions they have taken and consumption decisions they have made. The most prominent consumer risk in recent years has been cigarette smoking, which has been the object of required hazard warnings, partial advertising bans, annual surgeon general's reports, restrictions on public smoking, and widespread adverse publicity.

This paper utilizes detailed data on individual risk perceptions and smoking behavior to investigate cigarette smoking as a potentially risky consumption activity. Two classes of issues are of interest. First, to what extent do individuals have accurate perceptions of the risk? Systematic biases in these risk perceptions are of policy interest from

I obtained the data used in this study as a part of my work supporting the smoking litigation efforts of Jones, Day, Reavis \& Pogue. Research support was provided by the endowment of the George G. Allen chair. Sharon Tennyson provided excellent research assistance. Sam Peltzman and two referees provided helpful suggestions.

[Journal of Political Economy, 1990, vol. 98, no. 6]

(C) 1990 by The University of Chicago. All rights reserved. $0022-3808 / 90 / 9806-0007 \$ 01.50$ 
both the standpoint of market efficiency and the role of hazard warnings, which ideally should foster more accurate risk perceptions. Individuals frequently overestimate highly publicized risks, and this pattern is borne out in an analysis of lung cancer risk perceptions.

The second class of issues pertains to the linkage between risk perceptions and smoking behavior. If risk perceptions did not affect smoking in a significant manner, then doubt would be cast on the rationality of these consumption decisions. In the case of lung cancer risks, smoking behavior is very responsive to risk perceptions in the expected direction.

This analysis of smoking behavior serves as a more general study of the character of risk-taking behavior. Much of the economic literature dealing with consumer and worker responses to risk is based on an assumption of rational individual responses to risk. Although evidence of rationality has been manifested in diverse ways by, for example, individuals' utilization of seatbelts and the positive effect of job risks on wage rates, these studies almost invariably have not focused on the components of the individuals' decision-making process. ${ }^{1}$ This cigarette smoking analysis provides a more refined exploration of the relationship of market responses to subjective risk perceptions than has appeared in any other context.

The character of the data requires that the analysis focus on static consumption decisions. What are individuals' risk perceptions and tastes, and how do these affect observed smoking behavior? Crosssectional data do not, however, permit us to consider decisions to quit smoking. The costs associated with such changes have been recently designated a problem of "addiction" by the surgeon general, in contrast with earlier designations: "The tobacco habit should be characterized as an habituation rather than an addiction" (U.S. Department of Health, Education, and Welfare 1964, p. 34). ${ }^{2}$ Some recent economic contributions suggest that our interpretation of this "addiction" phenomenon is quite complex. ${ }^{3}$ Costs of change are relevant from the standpoint of market failure if individuals make mistaken decisions that they wish to reverse. The welfare losses will hinge on the nature of the risk perceptions that will be explored here. ${ }^{4}$

${ }^{1}$ See, among others, Peltzman (1975) for a study of seatbelts and Viscusi (1979) for an analysis of job risks. The only study of wage responses to subjective job risk perceptions using a continuous risk measure is Viscusi and O'Connor (1984). The first study using a 0-1 measure of subjective risk perceptions is Viscusi (1979). Other pertinent studies of risk consumption decisions include Peltzman (1973, 1987); Schneider, Klein, and Murphy (1981); Viscusi and Magat (1987); and Viscusi, Magat, and Huber (1987).

${ }^{2}$ Recent statements on addiction appear in the New York Times (May 17, 1988, p. 1). For more detail, see also U.S. Department of Health and Human Services (1988).

${ }^{3}$ See Stigler and Becker (1977), Schelling (1984), and Becker and Murphy (1988) for discussions of the addiction phenomenon from different perspectives.

${ }^{4}$ This point is discussed in Viscusi (1979) with respect to transactions costs of changing jobs that are risky and have uncertain properties. The pivotal issue is the nature of 
In Section II of the paper, I describe the data set that will be used, the conceptual background, and the empirical model. Section III provides a detailed analysis of lung cancer risk perceptions, and Section IV presents the smoking equation results. In Section V, I explore the risk perception equivalent of excise taxes. Section VI offers concluding observations on smoking as a potentially risky consumption decision.

The results indicate that the level of lung cancer risk perceptions is very high. Not only do individuals have substantial lung cancer risk assessments that influence their smoking decisions, but excise taxes discourage smoking further by, in effect, endowing people with the equivalent of risk perceptions almost comparable to their current risk beliefs. The enormous social pressures being exerted against cigarette smoking will surely affect individual perceptions of the product risk, so that the substantial role of risk perceptions accords with expected behavior.

\section{The Data Base}

In September 1985, a New York survey research firm, Audits and Surveys, undertook a national telephone survey to ascertain the character of individual attitudes toward smoking and the nature of their risk perceptions. ${ }^{5}$ The sampling procedure involved used over 400 phone banks to call individuals nationwide; the sampling was proportional to the number of working residential phones in each stratum of the sample. To ensure a representative sample, the stratification was first performed by region (the four U.S. census regions), which were then stratified into metropolitan and nonmetropolitan areas.

Once contact was made with a home, a random selection procedure was used to determine which household participant would be interviewed, with participation restricted to persons aged 16 and older. Just over half of the sample are in the large middle-aged cohort ages 22-45, one-tenth are aged $16-21$, and the remainder are over age 45 . Over half of the sample are females, and the average household size is 2.1 .

After informing the individual answering the phone that this survey was being conducted for "a study about cigarette smoking" and selecting the survey respondent from the household, the interviewer first ascertained the respondent's overall reaction to cigarettes. As indicated by Magat, Viscusi, and Huber (1988), this open-ended

risk perceptions at the onset of consumption activity. For the data set considered here, the younger members have even higher risk perceptions than the sample average.

${ }^{5}$ The survey was undertaken by this survey research firm in support of tobacco litigation efforts. 
memory recall approach is an instructive technique for assessing the saliency of taste-related factors and risk-related concerns without biasing subsequent responses.

After then determining which of several statements the individual had heard about cigarettes (e.g., "cigarette smoking is bad for a person's health, but not dangerous"), the interviewer ascertained the respondent's perception of the risks of lung cancer, which has long been viewed as a prominent and substantial potential hazard of cigarettes. Obtaining meaningful survey responses regarding individuals' risk perceptions is not a straightforward task since one could ask for a probability, a number of deaths for a base population, or a rating on a risk scale shown to the respondents. For a phone interview, visual risk scales are infeasible, so the approach used was to ascertain the lung cancer risk per 100 smokers: "Among 100 cigarette smokers, how many of them do you think will get lung cancer because they smoke?" As is discussed in Viscusi and Magat (1987), this approach of using a base population reference point is a more readily understood method for eliciting probabilistic information than explicitly dealing with probabilities or fractions. The individual's response to the lung cancer question is divided by 100 , to obtain the lung cancer probability (RISK), which averaged .426 for the sample. Because of the central importance of the risk perception variable to the analysis, the empirical investigation is restricted to the 3,119 individuals for whom values of RISK were not missing.

In a different survey context (see Viscusi 1988), I have obtained similar estimates of the assessed cancer death risk from smoking. In particular, consumers were asked to rate the severity of a particular test product on a risk scale in which risks posed by cigarettes and saccharin products were the principal reference points. Respondents indicated that the test product posed a risk that was equivalent to smoking 0.58 packs of cigarettes daily. They were then asked how many of the 11 million Illinois residents using the product would be killed by consumption of the product. Their average response of $1,316,729$ deaths indicated that they viewed a death risk of .12 as equivalent to the risk posed by 0.58 packs of cigarettes. The implied death risk per pack is .21, which leads to an overall average death risk from cigarettes of .33 based on current population smoking rates. ${ }^{6}$ Given the less representative character of the food cancer warning study and the quite different survey approaches, these findings are

${ }^{6}$ In my food cancer warning study (Viscusi 1988), individuals' responses to different risk questions indicated an assessed cancer death risk of .21 per pack of cigarettes smoked per day, which led to an implied death risk of .33 based on 1980 data on the number of cigarettes smoked from the Tobacco Institute $(1987$, p. 6$)$. Information on the number of smokers appears in U.S. Department of Commerce (1985, p. 119). 
quite similar to the Audits and Surveys data. Establishing this linkage also suggests that the results in this paper are likely to be reasonably robust with respect to variations in survey methodology.

Unfortunately, the survey did not include information on all components of smoking risks. For example, although there is a high mortality risk from lung cancer, it would have been helpful to have had information on the assessed mortality from lung cancer, not simply assessed lung cancer rates. The previously mentioned survey by Viscusi (1988) did address the cancer mortality risk component, yielding similar but somewhat smaller estimates than those for the overall lung cancer risk.

More important, there are other mortality and morbidity risks associated with smoking, including heart disease, strokes, and emphysema, but these are not included in the survey data. Although the perspective afforded by this analysis will be limited to the link between lung cancer risk perceptions and smoking behavior, other surveys (1981 Gallup poll) indicate that lung cancer risk awareness is similar to that for other diseases, such as throat cancer and heart disease.

The other variables of interest pertain to the individual's smoking status. One-fourth of the respondents were current cigarette smokers, and an almost identical number were former cigarette smokers. Half of the sample had never smoked cigarettes. The smoking fraction is a bit below the national average, ${ }^{7}$ which is not unexpected given the overrepresentation of women in the sample.

\section{Individual Perceptions of Lung Cancer Risks}

The central focus of this paper is perceptions of smoking risks and the linkage of these perceptions to smoking behavior. The nature of these risk perceptions has long been a matter of policy controversy, and the government has mandated a series of increasingly stringent on-product warnings in order to increase the perceived risk.

Previous evidence on smoking risk perceptions has not been based on a meaningful probabilistic metric. For example, the U.S. Federal Trade Commission (1981, pp. 3-5) concluded that the stronger series of rotating warnings initiated in 1984 was needed since many smokers did not believe that smoking is "hazardous" or "causes cancer." Such survey approaches are deficient in at least three ways. First, they often deal with statements for which the implied risk level is unclear. What level of risk is sufficient for an activity to be classified "hazardous"?

${ }^{7}$ The U.S. average smoking percentage was 32.1 in 1983 (see U.S. Department of Commerce 1985, p. 119). 
The risk threshold is undefined and may vary greatly across respondents. Second, the questions posed often treat risks that are probabilities as if they were nonstochastic. It is not correct to state that smoking "causes cancer" since this wording implies a certain link, whereas the true relationship is probabilistic. Third, even though individuals may not give correct responses to quiz questions on cigarette smoking trivia (e.g., what fraction of lung cancer is caused by cigarette smoking?), their overall risk judgments may be correct.

The RISK variable analyzed here consequently represents a considerable improvement over the smoking literature in terms of providing a meaningful risk measure. To assess the extent of bias in RISK perceptions, one must make some judgment regarding the actual lung cancer risk level. Such judgments are difficult to make since the scientific evidence is imprecise, and the scientific results are based largely on overall fatality risks of smokers as opposed to the specific contribution of cigarettes to lung cancer. Since cigarettes smoked in earlier decades had a much stronger tar and nicotine content than those smoked in the survey year (1985) and since smokers are more likely to engage in a variety of life-endangering pursuits, the evidence on estimated lung cancer risk levels may be biased upward. With these caveats in mind, I shall take as my estimate of the "true" lung cancer risk a value in a range from .05 to .10 ; this estimate has been generated using information from the surgeon general's reports. ${ }^{8}$ In recognition of the uncertainty regarding the "true" lung cancer risk reference point, a sensitivity analysis will be performed using these two different reference points. These reference lung cancer risk levels are primarily an expositional device for putting the empirical results in perspective. A change in the reference risk level to .20, for example, would alter the implications of the results very little. However, an increase in the risk level to a figure such as .60 , which is well out of line with any risk estimates in the literature, would necessitate a change in the nature of the discussion.

The distribution of lung cancer risk perceptions for the full sample and for smokers appears in table 1. The average value of RISK for the population is .426 . The levels differ by smoking status since smokers have a lower risk assessment.

Not only is there no evidence of a downward bias in risk percep-

${ }^{8}$ In particular, there are 110,000 lung cancer deaths per year, 85 percent of which are believed to be due to smoking (U.S. Department of Health and Human Services $1982, \mathrm{p}$. vi). This death rate represents a lung cancer risk of .0017 per year of smoking, i.e., the number of lung cancer deaths divided by the number of smokers (U.S. Department of Commerce 1985, p. 119). For lifetime smoking periods ranging from 30 to 60 years, which is likely to be excessively long, the associated risk ranges from .05 to .10 . Since the mortality rate in 5 years for untreated lung cancer cases is 95 percent, the risk ranges for lung cancer overall and fatal cases of lung cancer are similar. 
TABLE 1

Distribution of Lung Cancer Risk: Perceptions for Cigarette SMoking

\begin{tabular}{ccc}
\hline \hline & \multicolumn{2}{c}{ FraCtION WITH RISK } \\
PERCEPTIONS IN INTERVAL \\
\cline { 2 - 3 } $\begin{array}{c}\text { DISTRIBUTION OF } \\
\text { LUNG CANCER RISK }\end{array}$ & $\begin{array}{c}\text { Full } \\
\text { PERCEPTIONS (RISK) }\end{array}$ & $\begin{array}{c}\text { Current } \\
\text { Smomple }\end{array}$ \\
\hline RISK $<.05$ & .052 & .092 \\
$.05 \leq$ RISK $<.10$ & .046 & .051 \\
$.10 \leq$ RISK $<.20$ & .117 & .130 \\
$.20 \leq$ RISK $<.30$ & .136 & .146 \\
$.30 \leq$ RISK $<.40$ & .090 & .114 \\
$.40 \leq$ RISK $<.50$ & .052 & .050 \\
$.50 \leq$ RISK $<.60$ & .239 & .228 \\
$.60 \leq$ RISK $<.70$ & .070 & .056 \\
$.70 \leq$ RISK $<.80$ & .084 & .050 \\
$.80 \leq$ RISK $<.90$ & .042 & .027 \\
$.90 \leq$ RISK $<1.0$ & .041 & .028 \\
RISK $=1.0$ & .030 & .026 \\
Mean RISK $*$ & .426 & .368 \\
& $. .005)$ & $(.009)$ \\
Sample size & 3,119 & 779 \\
\hline
\end{tabular}

NOTE.-Standard errors of the means are in parentheses.

tions on average, but few people underestimate the lung cancer risk. For the "true" lung cancer risk level $.05,5.2$ percent of the full sample and 9.2 percent of the smokers underestimate the risk, and for a "true" risk of .10, the percentage underestimating the risk rises to 9.7 for the full sample and to 14.4 percent for smokers. In each case, many more individuals overestimate the risk than underestimate it.

Moreover, because the reference lung cancer risk levels are closer to zero than to one, the magnitude of the possible overestimation is greater as well. Consider the results for a true risk value of .05 . For the full sample, individuals who underestimate the risk do so by an average amount of .02, whereas individuals who overestimate the risk do so by .465. For the full sample, the extent of overestimation is over 20 times as great as the amount of underestimation, and the frequency of overestimation is over nine times as great. Individuals consequently are more prone to overestimate the risk and to err in their overestimation by a substantial amount.

The survey's focus on lung cancer risks limits our ability to generalize about other smoking risk perceptions, such as those for cardiovascular disease and morbidity effects. As a result, any conclusions in this section relating to biases in risk perceptions pertain to lung cancer risks, not to all components of smoking hazards. If all other risk components are biased in the same manner, then the results suggest 
that smoking risks are greatly overestimated. Even if all other risk perceptions were zero, the dramatic overassessment of lung cancer risks would have important implications for any assessment of the likelihood of market failure. Recent estimates suggest that recognition of all causes of death from cigarettes, not simply lung cancer, would roughly triple the estimated death risk-a risk estimate that appears well below the average risk perception. ${ }^{9}$

The finding that individuals overestimate lung cancer risks of smoking is quite consistent with the literature on the psychology and economics of risk perceptions. A large number of studies have demonstrated a tendency to overestimate low-probability events and underestimate high-probability events (Fischhoff et al. 1981; Viscusi 1985; Viscusi and Magat 1987). As I show in Viscusi (1985), this tendency does not represent a behavioral irrationality but stems from a rational Bayesian learning process in which one revises one's prior beliefs toward the truth. In the case in which learning is partial, the posterior probability of low-probability events will exceed the actual risk, and for high-probability events, assessments will be below the risk. In the limiting full-information case, risk perceptions will be accurate.

A second, related observation stems from the literature on highly publicized events. Risks from accidents that have received widespread publicity are more likely to be overestimated (see Combs and Slovic 1979; Fischhoff et al. 1981). Publicity relating to smoking hazards has long been prominent. In recent decades, there has been an annual surgeon general's report critical of cigarettes, as well as mandatory labeling and advertising restrictions. Extensive media coverage and social pressure also are no doubt influential. The overestimation of the lung cancer risks in the presence of such substantial "information" does not indicate a failure in individuals' ability to learn, but rather the character of the information provided. These informational efforts indicated a risk, but not its magnitude.

\section{Determinants of Smoking Behavior}

\section{The Smoking Probability Equation}

To model the discrete cigarette smoking decision, consider the following simple one-period model. Let there be two states of the world, life and death. When alive, the individual reaps a utility $U$ (smoke) if he or she smokes and $U$ (don't) if he or she does not smoke. Death offers a

\footnotetext{
${ }^{9}$ The total death risk estimate of 300,000 deaths per year comes from the U.S. Department of Health and Human Services (1988, p. iii). The lung cancer risk estimates were discussed in n. 8 .
} 
payoff $V$, and the probability of death is $s$ if one smokes and zero otherwise. An individual will smoke if

$$
(1-s) U(\text { smoke })+s V>U(\text { don't }),
$$

or

$$
[U(\text { smoke })-U(\text { don't })]+s[V-U(\text { don't })]>0 .
$$

The first term in equation (1) represents the net utility gain from cigarette smoking, which reflects both taste factors and prices, and the second term represents the expected utility loss from death.

Let us parameterize equation (1) with a linear model, letting $\boldsymbol{\beta}_{i}(i=$ $1,2)$ be the coefficient vectors, $\mathbf{Y}_{1}$ be a vector of taste and price variables, $\mathbf{Y}_{2}$ be a vector of variables affecting utility loss, and $u_{2}$ be a random error term. The smoking decision is attractive if

$$
\boldsymbol{\beta}_{1} \mathbf{Y}_{1}+\boldsymbol{\beta}_{2} s \mathbf{Y}_{2}+u_{2}>0
$$

or

$$
\begin{aligned}
\operatorname{Pr}(\text { smoke }) & =\left[\operatorname{Pr}\left(\boldsymbol{\beta}_{1} \mathbf{Y}_{1}+\boldsymbol{\beta}_{2} s \mathbf{Y}_{2}\right)>-u_{2}\right] \\
& =\left[1+\exp \left(-\boldsymbol{\beta}_{1} \mathbf{Y}_{1}-\boldsymbol{\beta}_{2} s \mathbf{Y}_{2}\right)\right]^{-1},
\end{aligned}
$$

if we assume a logistic probability distribution.

Table 2 presents four alternative specifications that represent different estimations of equation (2) above. Each equation includes a series of seven regional dummy variables to capture regional differences in prices and tastes for cigarettes. Equation 1 in table 2 includes a basic set of four demographic variables to capture smoking tastes (two age group variables, household size, and sex) and a RISK variable to capture smoking losses. The smoking loss will be treated as a constant dependent only on RISK. As expected, higher perceived risks of cigarette smoking reduce the smoking probability. Although the RISK variable could potentially be endogenous, this possibility is explored and rejected. ${ }^{10}$ There is also a potential bias in the RISK coefficient arising from the omission of types of risk other than lung cancer risk. ${ }^{11}$

${ }^{10}$ Following the procedure in Hausman (1978), I included an instrumental variables estimate for RISK in the equations reported in table 2 as a specification test for endogeneity of RISK. The test coefficients (standard errors) are $-.1601(.2471)$ for eq. 1 , $-.1564(.2469)$ for eq. $2, .0040(.1754)$ for eq. 3 , and .0071 (.1753) for eq. 4, easily passing the endogeneity test in all four cases. The test of overidentifying restrictions for the excluded instruments is also passed.

${ }^{11}$ In particular, the overall risk $s_{i}$ for person $i$ may be given by $s_{i}=\mathrm{RISK}_{i}+u_{i}$. Inclusion of the risk information variables (eqq. 2 and 4) and smoking attitude variables (eqq. 3 and 4) will capture some of the omitted risk influences. Estimations using instrumental variable sets based on 50 regional dummy variables and a $0-1$ variable for whether RISK was above or below its median value yielded very similar results. Because 
Equations 2 and 4 in table 2 include a set of four information variables, such as whether respondents have heard that smoking reduces life expectancy, to capture aspects of risk perceptions not fully captured by RISK. Equations 3 and 4 include attitude probe variables regarding respondents' overall reaction to cigarettes, which was generally negative. The attitude probe variable set captures both tasterelated factors and factors related to risk perceptions. In all cases, the RISK variable continues to have a significant positive effect on smoking.

\section{The Effect of Unbiased Perceptions}

A principal policy and welfare issue is what effect accurate risk perceptions would have on smoking behavior. If individuals who underestimated the risk or overestimated the risk had a more accurate risk perception and acted on it, what effect would there be on smoking behavior? Although the data do not make it possible to undertake such an assessment for all smoking risks, we can analyze how responsive smoking decisions would be to different lung cancer risk assessments.

Using the results in table 2 (eq. 1), one can undertake such calculations by replacing the individual's actual risk perceptions with an estimate of the true risk. Because of the nonlinearity of the logit estimation procedure, the approach here will not be to examine the effects at the variable mean but rather will be a complete simulation. For each of the 3,119 sample members, I calculate the predicted smoking probability on the basis of their reported risk perceptions and the predicted probability with accurate risk perceptions. These calculations were undertaken for two "true" lung cancer risk levels: .05 and .10 .

Table 3 summarizes the results of these calculations. Consider first the results for the case of a "true" risk of .05. For individuals who underassess the risk, they do so by very little, so that accurate risk perceptions would diminish their smoking probability by .009 , or under 1 percent. For individuals who do not underassess the risk, the smoking probability would increase substantially-by .082 -if risk perceptions were unbiased.

To ascertain the overall effect on societal smoking rates, these estimates must be weighted by the fraction of individuals in the group. Since many more individuals overassess or correctly assess the risk

of the inherent difficulty in finding instruments correlated with the lung cancer risk but not the omitted risks, the potential for bias cannot be completely eliminated. Other studies of market responses to risk, such as studies of wage effects of fatality risks, are subject to similar limitations. 


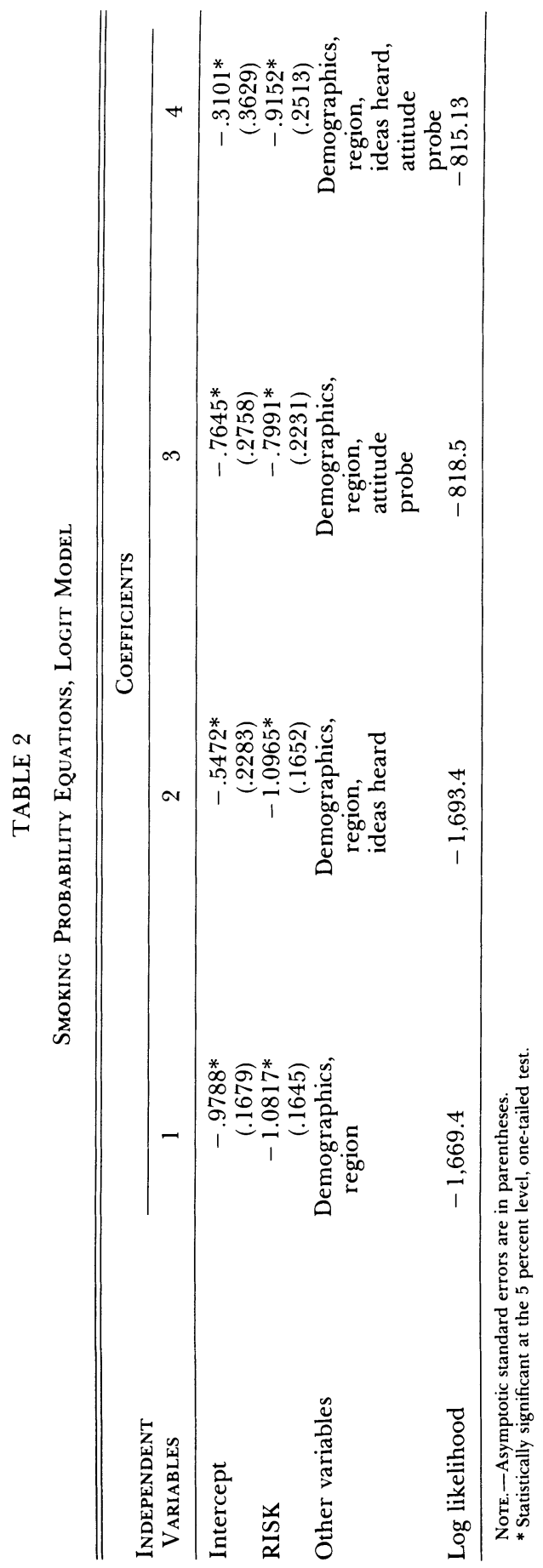


TABLE 3

Effect of Lung Cancer Risk Perception Biases on Smoking Probability

\begin{tabular}{|c|c|}
\hline & Fraction or Probability \\
\hline & A. True Lung Cancer Risk $=.05$ \\
\hline \multicolumn{2}{|l|}{ Underassess risk $($ RISK $<.05)$ : } \\
\hline Fraction of sample & .052 \\
\hline Current smoking probability & .337 \\
\hline \multicolumn{2}{|l|}{ Smoking probability if accurate } \\
\hline Change in smoking probability & -.009 \\
\hline \multicolumn{2}{|l|}{ Do not underassess risk (RISK $\geq .05$ ): } \\
\hline Fraction of sample & .948 \\
\hline Current smoking probability & .245 \\
\hline \multicolumn{2}{|l|}{ Smoking probability if accurate } \\
\hline perceptions (i.e., RISK $=.05$ ) & .327 \\
\hline \multirow[t]{2}{*}{ Change in smoking probability } & +.082 \\
\hline & B. True Lung Cancer Risk $=.10$ \\
\hline \multicolumn{2}{|l|}{ Underassess risk (RISK $<.10)$ : } \\
\hline Fraction of sample & .097 \\
\hline Current smoking probability & .329 \\
\hline \multicolumn{2}{|l|}{ Smoking probability if accurate } \\
\hline perceptions (i.e., RISK $=.10$ ) & .313 \\
\hline Change in smoking probability & -.016 \\
\hline \multicolumn{2}{|l|}{ Do not underassess risk (RISK $\geq .10$ ): } \\
\hline Fraction of sample & .903 \\
\hline Current smoking probability & .241 \\
\hline \multicolumn{2}{|l|}{ Smoking probability if accurate } \\
\hline perceptions (i.e., RISK $=.10$ ) & .315 \\
\hline Change in smoking probability & +.074 \\
\hline
\end{tabular}

rather than underassess the risk (.948 vs. .052), the societal effect is driven almost entirely by the influence of those who do not underassess the risk. Overall, accurate lung cancer risk perceptions would boost the societal smoking rate by 7.5 percent. Smoking rates would increase by roughly one-fourth of their current levels if people believed that the true lung cancer risk was .05 .

These results are not particularly sensitive to increases in the reference lung cancer risk level that is assumed since overassessments of the risk are of greater magnitude. For the reference risk value of .10, the decreased smoking probability of those who underassess the risk is almost double that of before, but the population share with this response remains small. The decreased smoking probability of those who do not underassess the risk has dropped somewhat, and a change of equal consequence is that the fraction of individuals in this group has dropped as well. The net effect is that the societal smoking rate would rise by 6.5 percent if individuals had an accurate understanding of a "true" risk level of .10. 
The role of risk underestimation for lung cancer risks is dwarfed by the effect of risk overestimation. An unbiased assessment of these risks would boost cigarette smoking because of the skewed distribution of risk perceptions around the actual lung cancer risk level.

\section{The Lung Cancer Risk Equivalent of Excise Taxes}

In situations of market failure involving goods traded on the market, a frequently suggested remedy for market failure is the use of taxes. Thus economists have suggested injury taxes for on-the-job injuries and various kinds of pollution taxes and marketable pollution rights schemes for pollution. These tax approaches have a direct analogue in the case of cigarettes since one could impose a tax on cigarettes to discourage consumption in much the same manner that would be accomplished through risk perceptions. Indeed, a recent analysis by Manning et al. (1989) explicitly addresses whether taxes on cigarettes and alcohol are sufficient to cover the external costs generated. Unlike information policies, however, taxes will discourage the consumption of all consumers, not simply those who underassess the risk.

Table 4 summarizes the excise tax percentage of cigarette prices by state. These percentages range from 20.3 percent in Virginia to 41.1 percent in Oregon. The national average is 30.8 percent, so that by any standard, cigarettes are a heavily taxed commodity.

The objective of this analysis is to establish the lung cancer risk equivalent of these excise taxes. In particular, what is the equivalent endowment of lung cancer risk perception that establishes the same effect on smoking probabilities that the cigarette excise tax does? In particular, the RISK increment $\Delta \mathrm{RISK}_{i}$ for individual $i$ has the same effect as current excise taxes, or

$$
\begin{gathered}
\operatorname{Pr}\left(\text { smoke }_{i} \mid \mathrm{RISK}_{i}, \text { excise tax }_{i}\right) \\
=\operatorname{Pr}\left(\text { smoke }_{i} \mid \mathrm{RISK}_{i}+\Delta \mathrm{RISK}_{i}, \text { excise tax }_{i}=0\right),
\end{gathered}
$$

where this equality is maintained using the results from the estimates in table 3 (eq. 1).

To establish this equivalence, one needs an estimate of the price elasticity of cigarette purchases. Four such elasticities are used in the calculations in table 4 ; they range from -0.4 to -1.4 . This range spans most of the elasticity estimates in the literature. Most estimates fall in the $(-0.4,-1.0)$ range, with higher elasticities such as -1.4 being reported for teenagers. ${ }^{12}$

\footnotetext{
12 Russo (1987) provides an excellent survey of the elasticity estimates. See Lewit and Coate (1982) for the elasticity estimate for teenagers.
} 


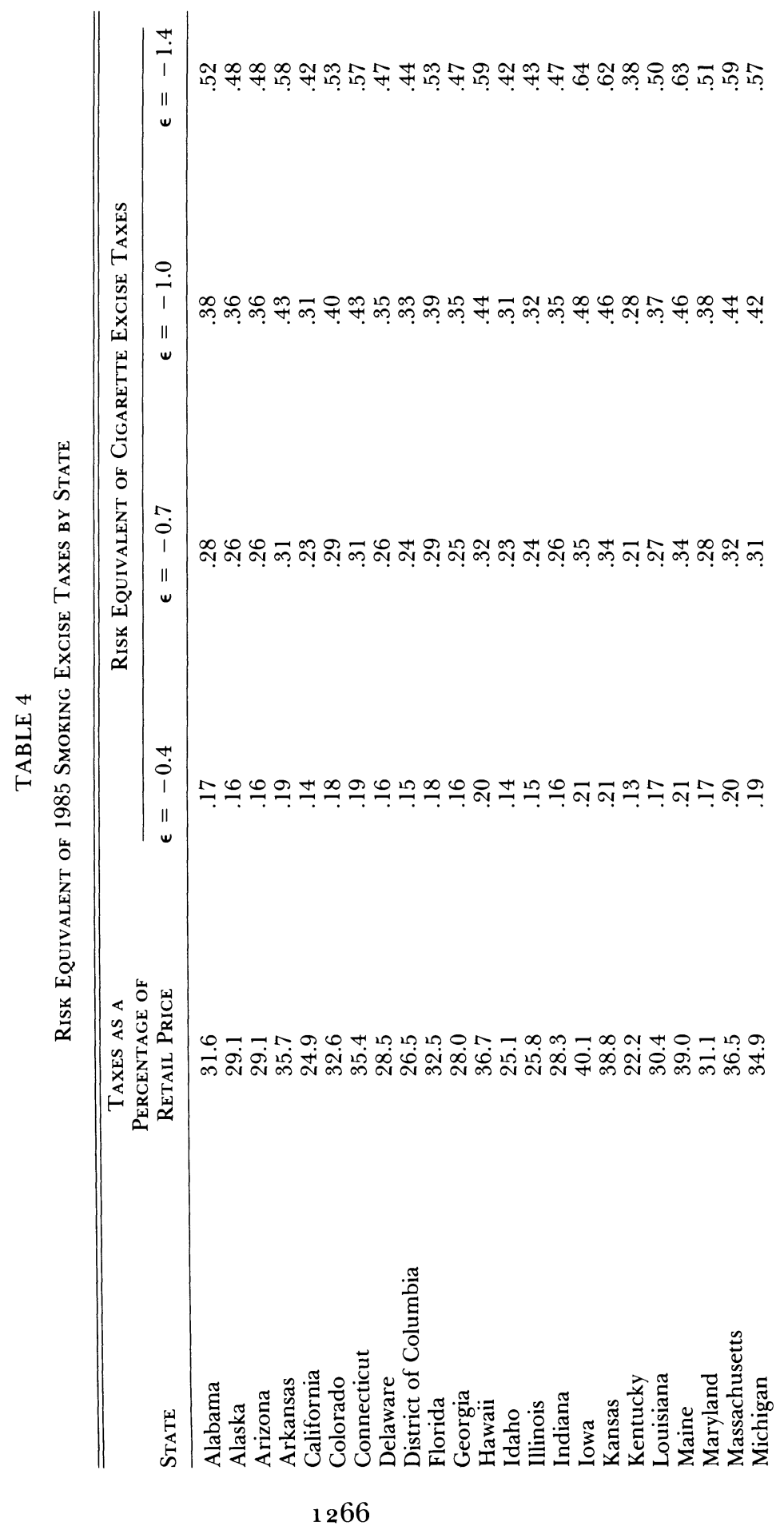




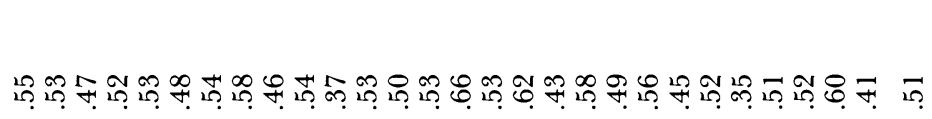
ఈ

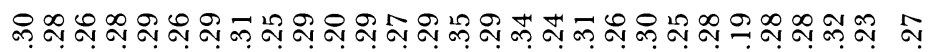

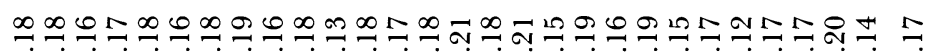

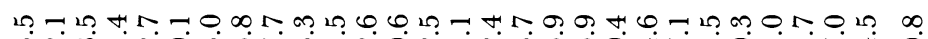

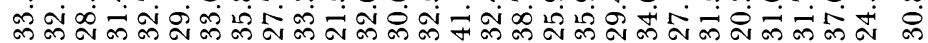

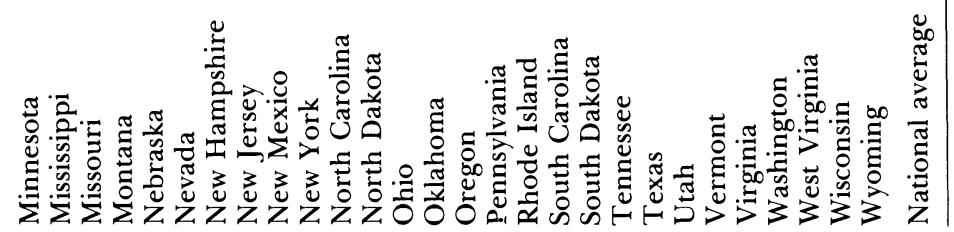


The results of the excise tax simulation in table 4 are quite striking. Even for the lowest-elasticity column the risk equivalent of the excise tax greatly exceeds estimates of the "true" lung cancer risk, with the risk equivalent being .17 nationally. The effects increase almost proportionally in the other elasticity cases.

Even if individuals had no awareness of lung cancer risks at all and assessed the risks as being zero, excise taxes would have discouraged smoking by more than the effect of accurate risk perceptions. Taxes augment the role of lung cancer risk perceptions by roughly half to more than double, depending on the price elasticity of demand. Whether or not these taxes are sufficient to offset possibly inadequate risk perceptions for other smoking risks is less clear-cut since the levels of the other risks from smoking are not as well established.

\section{Conclusion}

From an economic standpoint, cigarette smoking can be viewed as a potentially hazardous consumption activity. The fundamental economic question is whether smoking decisions are made in a rational manner. The assessment of the role of one important smoking risk, that of lung cancer, indicates that these risk perceptions are quite substantial and are perhaps biased upward. This is consistent with psychological evidence on highly publicized risks. The source of the biased perceptions may also be a consequence of the character of societal information transfer and the social pressure against smoking.

Perceptions of the risks also influence smoking behavior, as predicted by an economic model of risky consumption behavior. The role of excise taxes serves to discourage consumption in much the same manner as increasing lung cancer risk perceptions by as much as 50 100 percent would, depending on the elasticity of demand. Cigarette excise taxes do more to reduce smoking propensities than elimination of any proclivities toward smoking stemming from underestimation of the potential lung cancer hazards. Although this study did not address all facets of smoking risks and decisions, the influence of lung cancer risk perceptions on smoking behavior provides striking evidence of the importance of individual responses to risk.

\section{References}

$\rightarrow$ Becker, Gary S., and Murphy, Kevin M. "A Theory of Rational Addiction." J.P.E. 96 (August 1988): 675-700.

Combs, Barbara, and Slovic, Paul. "Newspaper Coverage of Causes of Death." Journalism Q. 56 (Winter 1979): 837-43.

Fischhoff, Baruch, et al. Acceptable Risk. Cambridge: Cambridge Univ. Press, 1981. 
Hausman, Jerry A. "Specification Tests in Econometrics." Econometrica 46 (November 1978): 1251-71.

Lewit, Eugene M., and Coate, Douglas. "The Potential for Using Excise Taxes to Reduce Smoking." J. Health Econ. 1 (August 1982): 121-45.

Magat, Wesley; Viscusi, W. Kip; and Huber, Joel. "Consumer Processing of Hazard Warning Information." J. Risk and Uncertainty 1 (June 1988): 20132.

Manning, Willard; Keeler, Emmett; Newhouse, Joseph; Sloss, Elizabeth; and Wasserman, Jeffrey. "The Taxes of Sin: Do Smokers and Drinkers Pay Their Own Way?" J. American Medical Assoc. 261, no. 11 (1989): 1604-9.

$\rightarrow$ Peltzman, Sam. "An Evaluation of Consumer Protection Legislation: The 1962 Drug Amendments." J.P.E. 81 (September/October 1973): 1049-91.

$-\rightarrow-$ "The Effects of Automobile Safety Regulation." J.P.E. 83 (August 1975): 677-725.

$\longrightarrow \rightarrow-$ "The Health Effects of Mandatory Prescriptions." J. Law and Econ. 30 (October 1987): 207-38.

Russo, Gerard. "An Empirical Analysis of Cigarette and Physician Demand." Working paper. Honolulu: Univ. Hawaii at Manoa, 1987.

Schelling, Thomas C. Choice and Consequence. Cambridge, Mass.: Harvard Univ. Press, 1984.

$\rightarrow$ Schneider, Lynne; Klein, Benjamin; and Murphy, Kevin M. "Governmental Regulation of Cigarette Health Information." J. Law and Econ. 24 (December 1981): 575-612.

$\rightarrow$ Stigler, George J., and Becker, Gary S. "De Gustibus Non Est Disputandum." A.E.R. 67 (March 1977): 76-90.

Tobacco Institute. The Tax Burden on Tobacco: Historical Compilation. Vol. 21. Washington: Tobacco Inst., 1987.

U.S. Department of Commerce. Bureau of the Census. Statistical Abstract of the United States, 1986. Washington: Government Printing Office, 1985.

U.S. Department of Health and Human Services. The Health Consequences of Smoking: A Report of the Surgeon General. Washington: Government Printing Office, various years.

U.S. Department of Health, Education, and Welfare. Smoking and Health: Report of the Advisory Committee to the Surgeon General of the Public Health Service. Princeton, N.J.: Van Nostrand, 1964.

U.S. Federal Trade Commission. Staff Report on the Cigarette Advertising Investigation. Washington: Government Printing Office, May 1981.

Viscusi, W. Kip. Employment Hazards: An Investigation of Market Performance. Cambridge, Mass.: Harvard Univ. Press, 1979.

—. "A Bayesian Perspective on Biases in Risk Perception." Econ. Letters 17, no. 1 (1985): 59-62.

- "Predicting the Effects of Food Cancer Risk Warnings on Consumers." Food and Drug Cosmetic Law J. 43 (March 1988): 283-307.

Viscusi, W. Kip, and Magat, Wesley A. Learning about Risk: Consumer and Worker Responses to Hazard Information. Cambridge, Mass.: Harvard Univ. Press, 1987.

$\rightarrow$ Viscusi, W. Kip; Magat, Wesley A.; and Huber, Joel. "An Investigation of the Rationality of Consumer Valuations of Multiple Health Risks." Rand $J$. Econ. 18 (Winter 1987): 465-79.

$\rightarrow$ Viscusi, W. Kip, and O'Connor, Charles J. "Adaptive Responses to Chemical Labeling: Are Workers Bayesian Decision Makers?” A.E.R. 74 (December 1984): 942-56. 